\title{
Treatment of Complicated Skin and Soft-Tissue Infections CAUSED BY RESISTANT BACTERIA: Value of Linezolid, Tigecycline, Daptomycin and Vancomycin
}

\author{
Christian Eckmann ${ }^{1}$ and Matthew Dryden ${ }^{2}$ \\ ${ }^{1}$ Klinikum Peine, Academic Hospital of Medical University Hannover, Germany \\ ${ }^{2}$ Royal Hampshire Hospital, Winchester, United Kingdom
}

\begin{abstract}
Antibiotic-resistant organisms causing both hospitaland community-acquired complicated skin and softtissue infections (cSSTI) are increasingly reported. A substantial medical and economical burden associated with MRSA colonisation or infection has been documented. The number of currently available appropriate antimicrobial agents is limited. Good quality randomised, controlled clinical trial data on antibiotic efficacy and safety is available for cSSTI caused by MRSA. Linezolid, tigecycline, daptomycin and vancomycin showed efficacy and safety in MRSA-caused cSSTI. None of these drugs showed significant superiority in terms of clinical cure and eradication rates.To date, linezolid offers by far the greatest number of patients included in controlled trials with a strong tendency of superiority over vancomycin in terms of eradication and clinical success..

Tigecycline is an alternative in polymicrobial infections except by diabetic foot infections. Daptomycin might be a treatment option for cases of cSSTI with MRSA bacteremia. cSSTI caused by resistant Gramnegative bacteria are a matter of great concern. The development of new antibiotics in this area is an urgent priority to avoid the risk of a postantibiotic era with no antimicrobial treatment options. An individual approach for every single patient is mandatory to evaluate the optimal antimicrobial treatment regimen.
\end{abstract}

\section{INTRODUCTION}

Skin and soft tissue infections (SSTI) are amongst the most common bacterial infections in humans. They represent one of the most common indications for antibiotic treatment and represent about $10 \%$ of hospital admissions in the US [1]. Amongst the broad spectrum of skin and soft tissue infections treatment is mainly delivered out of hospital. SSTI have a broad range of aetiology, clinical manifestation and severity $[2,3]$. At one end of the spectrum the outcome may be spontaneous resolution without antibiotics, but at the other end it may present with sepsis with lethal outcome. SSTI at $10 \%$ is the third most frequent focus for severe sepsis or septic shock, after pneumonia (55$60 \%$ ) and abdominal infections (25\%) [4].
This review aims to discuss the currently available antibiotics active against resistant bacteria (primarily MRSA, VRE, ESBL-producing bacteria and carbapenem-resistant strains) in terms of mechanisms of action, eradication rates and most important clinical outcome.

\section{Classification of Skin and Soft Tissue INFECTIONS}

The classification of skin and soft tissue infections is often confusing. Specific SSTI can be sub-categorised according to the causative microbial agents, the main tissue layer affected (i.e. skin, subcutis, fascia and muscle) or according to clinical signs and symptoms. It is to be differentiated, whether the infection is localised or generalised. Useful classifications are those which differentiate SSTI according to urgency of surgical intervention $[5,6]$. Three categories can be differentiated: Infections treated conservatively (i.e. erysipelas), infections with the need for surgical intervention (i.e. infective diabetic foot) and severe skin and soft tissue infections that require urgent surgery (i.e. necrotising fasciitis).

Another classification, provided by the FDA and frequently used for clinical trials differentiates between uncomplicated and complicated SSTI, whereby the latter group is characterised by either deep soft tissue involvement with signs of systemic sepsis, severe patient immunosuppression or the necessity for major surgical intervention [7].

The key to successful treatment of many severe soft tissue infections is based on early detection, adequate calculated antibiotic treatment and prompt surgical debridement.

\section{Aetiology And Spectrum of BACteria}

SSTI can be caused by a multitude of bacterial agents. The most important pathogenic agents are Gram-positive bacteria, primarily $S$. aureus and group A streptococci. In recent studies more than $50 \%$ of all SSTI were caused by staphylococcal or streptococcal species [8-11]. The aetiological spectrum also includes enterococci, Gram-negative and anaerobic bacteria with necrotising, gangrenous infections and those close to the trunk as well as bite injuries [12-14]. 
The past two decades have witnessed a massive increase in infections caused by pathogens that are resistant to commonly used antimicrobial agents [15-17]. The emergence and spread of drug-resistant bacteria has been facilitated by the selective pressure induced by intensive use of antibiotics both in hospitalized and out-patients. A growing number of invasive procedures, performed in increasingly multi-morbid patient populations and sometimes with inadequate infection control measures, have added to the problem [18]. Other factors driving the process include greater movement of people and the agricultural usage of antimicrobials [19].

This increase in infections is in contrast to a decrease in the number of novel antimicrobial therapeutic options with activity against drug-resistant pathogens [20]. The Antimicrobial Availability Task Force of the Infectious Diseases Society of America (IDSA), recently identified vancomycin-resistant Enterococcus faecium (VRE), methicillin-resistant Staphylococcus aureus (MRSA), Acinetobacter baumannii, Pseudomonas aeruginosa, and extended spectrum $\beta$-lactamase (ESBL)- producing Enterobacteriaceae as particularly problematic pathogens $[21,22]$.

An increased likelihood of drug-resistant organisms as causative pathogens has been reported in both hospital- and community-acquired complicated skin and soft-tissue infections (SSTI) [23]. A substantial medical and economical burden evoked by MRSA colonization or infection has been documented [24, 25]. In the US, community acquired MRSA (CA-MRSA) is the most frequent isolated bacteria in cSSTI [26]. Cases of necrotizing cSSTI caused by CA-MRSA are reported [27]. The epidemiological shift towards drug-resistant pathogens in the settings of complicated SSTI together with the limited number of currently available appropriate antimicrobial agents thus translates into relevant problems in a population of seriously ill patients.

\section{LINEZOLID}

Linezolid is an oxazolidinone antibiotic active against many resistant and susceptible Gram-positive organisms (including MRSA, VRE and macrolide-resistant streptococci [28]. Linezolid has an oral and an intravenous formulation with a bioavailability of $100 \%$. The tissue penetration into soft tissues in comparison to serum concentrations is 105\% [29]. Linezolid has been approved for the treatment of adult patients with complicated skin and skin structure infections with suspected or proven infections due to Gram-positive organisms including MRSA and VRE by the FDA and the EMA.

Linezolid has been studied extensively in the treatment of a broad range of skin infections [30-35]. A recently published systematic review and meta-analysis of linezolid versus vancomycin for MRSA skin and soft tissue infections [28] included four trials: three for clinical outcome $(\mathrm{n}=174)$ and three for microbiological outcome $(n=439)$. For clinical outcomes there were non-significant trends in favour of linezolid (RR 0.34 ; 95\% CI 0.04, 2.89; $\mathrm{p}=0.32$ ). For microbiological outcome there was weak evidence of linezolid outperforming vancomycin (RR 0.55; 95\% CI 0.30; $\mathrm{p}=0.05$ )
[28]. In one study designed to evaluate the potential for linezolid to provide superior efficacy to vancomycin in the treatment of cSSTI caused by known or suspected MRSA, a subgroup analysis of patients who had culture-proven MRSA indicated that linezolid might offer advantages over vancomycin, suggesting the need for a definitive study in this subgroup [33]. Therefore, a phase 4 clinical trial was designed to better define the relative efficacy of linezolid against appropriately dosed vancomycin for the treatment of cSSTI proven to be caused by MRSA. To address several design limitations of the previous trials, only patients with documented MRSA infections were included and the vancomycin dose was titrated according to patient weight, changing renal function, and vancomycin troughs [35]. 240 patients in the linezolid group and 221 patients in the vancomycin group were analyzed, representing the by far greatest number of patients with proven cSSTI caused by MRSA that has been investigated to date. The clinical success rate was significantly higher in linezolid-treated patients in the modified intent-to-treat population $(\mathrm{p}=0.048)$. The microbiological success rate was higher for linezolid at the end of treatment $(\mathrm{p}<0.001)$ and was similar at the end of the study $(p=0.127)$.

Linezolid offers the possibility of early switch to oral therapy and, consequently, early discharge, which may be of possible economic advantage, particularly in the field of cSSTI. This is discussed elsewhere in this issue.

Linezolid has been available for ten years now and is well established as an effective agent in cSSTI [15]. A dose reduction is not necessary in renal insufficiency. Its side effects of thrombocytopenia (2.2\%) and anaemia $(4.8 \%)$ are considered mild, reversible and duration dependent [36]. Mostly in patients treated longer than the recommended duration of 28 days, reversible and irreversible peripheral and optic neuropathy, lactic acidosis and serotonin syndrome have been observed [37].

\section{DAPTOMYCIN}

Daptomycin, a fermentation product of Streptomyces roseosporus, is a cyclic lipopeptide antibiotic with a rapid concentration-dependent bactericidal activity against Gram-positive bacteria in vitro including resistant and susceptible strains [38]. The good tissue penetration into soft tissues is another pharmacokinetic advantage. It is only available as an intravenous infusion.

Daptomycin has been approved for the treatment of adult patients with complicated skin and skin structure infections by the FDA and the EMA. In two phase III studies 534 patients have been treated with daptomycin in a dosage of $4 \mathrm{mg} / \mathrm{kg}$ body weight once daily for cSSTI. The clinical success rate for daptomycin was $83.4 \%$ in the daptomycin group and $84.2 \%$ in the comparator group (vancomycin $1 \mathrm{~g}$ bid and penicillinase-binding semisynthetic penicillin 4-12 g daily, respectively). The clinical success rate in MRSAcaused infections was $75 \%$ (21 of 28 patients) in the daptomycin group versus $69 \%$ in the vancomycin group. The percentage of patients with a successful therapy (clinical cure or improvement) of only 4-7 
days was significantly higher in the daptomycin group $(63 \%)$ than in the vancomycin group $(33 \%, p<0,0001)$ [10]. In a randomized trial with patients suffering from diabetic foot infections $(n=103)$ the treatment success with daptomycin and vancomycin was $71,4 \%$ and $69,4 \%$, respectively [39]. A sub-analysis of patients with evidence of MRSA has not been performed Specific trials addressing the efficacy and safety of daptomycin in cSSTI proven to be caused by MRSA have not been published yet. Daptomycin showed good efficacy in the treatment of MRSA caused bacteremia and / or infective endocarditis [40, 41]. Consequently, daptomycin has been recommended as a possible treatment option in patients with cSSTI caused by MRSA and a high risk or evidence for bacteremia [80].

Daptomycin is safe and well tolerated when administered once daily according to on label dosage (4 $\mathrm{mg} / \mathrm{kg}$ body weight). The most frequent documented side effects are of gastrointestinal origin (nausea, vomiting) $[10,41]$. In higher dosages $(6 \mathrm{mg} / \mathrm{kg}$ body weight) an increasing number of CPK elevations has been observed. This led to discontinuation of the drug in some cases [41]. A dose reduction is not necessary in renal insufficiency. In comparison to vancomycin, daptomycin was associated with a significantly lower rate of nephrotoxicity $(6,7 \%$ daptomycin versus $18,1 \%$ vancomycin) $[10,41]$. Its activity is independent of the cytochrome p450 system.

\section{TigeCYCLINE}

Tigecycline is a novel glycylcycline antibiotic for systemic use with broad-spectrum activity against aerobic and facultative Gram-positive and Gram-negative bacteria and anaerobic bacteria [42]. Tigecycline is active in vitro against antibiotic-resistant bacteria such as VRE (Enterococcus faecalis and E. faecium), MRSA, ESBL-producing Gram-negative and carbapenem-resistant bacteria [43, 44].

Tigecycline has been approved for the treatment of adult patients with complicated skin and skin structure infections by the FDA and the EMA. The patient population in the 2 phase III studies evaluating the use of tigecycline in cSSTI presented with a comparatively low mean (APACHE) II score [9].

There is a lack of data on the treatment of severely ill patients from the pivotal trials with tigecycline. Available data on the use of tigecycline in severely ill patients are mostly from retrospective analyses [45, 46] or studies with a focus on identified pathogens rather than the clinical picture [47-49].

Recently, data from prospective controlled trials on the efficacy and safety of tigecycline in the treatment of severely ill patients with complicated infections were published $[50,51]$. In one monocenter study including 207 patients (mean APACHE II score: 21) 8\% of the patients treated with tigecycline were found to suffer from cSSTI. The clinical success rate was $76 \%$ [50]. In a prospective observational multicenter trial including 656 patients (mean APACHE II score: 19) with tigecycline mono- or combination therapy, 102 patients $(15,5 \%)$ were defined as cSSTI. The spectrum of isolated bacteria frequently included resistant organisms (MRSA: $65 \%$ of all $S$. aureus isolates, VRE:
$14 \%$ of all enterococcal isolates, ESBL E. coli: 28\%). The clinical success rate was $82 \%$ [51].

Although in vitro activity has been proven [52], Tigecycline failed to reach non- inferiority over the comparator substance in a trial with patients suffering from diabetic foot infection (data on file). Therefore, the drug is to date not approved for this indication. Tigecycline is in general a well tolerated substance. Frequently observed side effects are of gastrointestinal origin (nausea, vomiting). Cases of acute pancreatitis following the administration of tigecycline have been observed [53]. A trend towards a higher mortality rates in patients treated with tigecycline in comparison to control subjects has been noticed [54]. The data from the pivotal trial with tigecycline versus vancomycin-aztreonam in cSSTI revealed a non-significant difference in mortality of $0.7 \%[9]$.

\section{VANCOMYCIN}

Vancomycin, a glycopeptide, has bactericidal activity against Gram-positive organisms in vitro including multiple-resistant (MRSA) and susceptible (MSSA) strains. It is only available as an intravenous infusion. The tissue penetration into soft tissue is poor (Table 1) [55]. It has been the gold standard for the treatment of MRSA infections for many years when no other drugs were available.

Vancomycin has been the comparator substance for numerous clinical trials of new substances (linezolid, daptomycin, tigecycline) for the treatment of cSSTI suspected or proven to be caused by MRSA (Table 2). Despite the pharmacokinetic weaknesses and the poor clinical results from other MRSA infections treated with vancomycin, none of these drugs showed significant superiority over vancomycin regarding clinical cure and eradication rates $[8,9,10,35]$. This probably reflects the paramount importance of surgical source control in many cSSTI, which in part masks the real clinical value of an antibiotic. Moreover, the study design (non-inferiority) and the study population (many studies did not meet the FDA criteria for complicated SSTI) may have prevented detection of significant differences [56]. Consequently, vancomycin is still an option in mild to moderate cSSTI caused by MRSA (Table 3).

Due to poor clinical results in treatment of MSSA and MRSA pneumonia and sepsis, there is increasing concern about the use of vancomycin in serious infections [57]. These data have led to the recommendation of combination with other drugs (primarily rifampicin), on the assumption that a combination might improve clinical outcome. However, the combination of vancomycin and rifampicin is not based on controlled clinical data. Potential side effects are interaction with the cytochrome P450 system and frequent development of resistance against rifampicin [58].

There have been efforts for optimising the dosage of vancomycin. A trough level of $>15 \mu \mathrm{g} / \mathrm{ml}$ has been recommended as desirable [59]. However, in a recently published trial comparing linezolid and vancomycin for the treatment of cSSTI caused by MRSA, the vancomycin dose was titrated according to patient 
Table 1. General characteristics of antibiotics with activity against MRSA.

\begin{tabular}{|c|c|c|c|c|c|}
\hline Antibiotic & Route & $\begin{array}{l}\text { Mechanism } \\
\text { of action }\end{array}$ & $\begin{array}{l}\text { tissue penetration } \\
\text { (\% of serum } \\
\text { concentration) }\end{array}$ & $\begin{array}{l}\text { In vitro Spectrum } \\
\text { of activity against } \\
\text { resistant bacteria }\end{array}$ & $\begin{array}{l}\text { Dose adjustment } \\
\text { necessary in renal } \\
\text { impairment }\end{array}$ \\
\hline Linezolid & i.v., oral & bacteriostatic & $105 \%$ & MRSA, VRE & No \\
\hline Tigecycline & i.v. & bacteriostatic & $91 \%$ & MRSA, VRE, ESBL, CRB & No \\
\hline Daptomycin & i.v. & bactericidal & $68,4 \%$ & MRSA, (VRE) & No \\
\hline Vancomycin & i.v. & bactericidal & $8-10 \%$ & MRSA & Yes \\
\hline TMP-SMX & i.v., oral & bactericidal & n.a. & MRSA & Yes \\
\hline Rifampicin & i.v., oral & bactericidal & n.a. & MRSA & Yes \\
\hline Fosfomycin & i.v. & bactericidal & $91 \%$ & MRSA & Yes \\
\hline Clindamycin & i.v., oral & bacteriostatic & $95 \%$ & MRSA & No \\
\hline Quino./dalfo & i.v. & bactericidal & n.a. & MRSA, (VRE) & Yes \\
\hline
\end{tabular}

$\mathrm{CRB}=$ carbapenem resistant bacteria

TMP-SMX = trimethoprim-sulfamethoxazole

(VRE) daptomycin = increasing number of treatment failures and emergence of resistance under therapy for VRE

(VRE) quinopristin/dalfopristin = no activity against E. faecium

Table 2. Assessment of antibiotics with activity against MRSA according to clinical data.

\begin{tabular}{|c|c|c|c|c|c|c|}
\hline Antibiotic & $\begin{array}{l}\text { Randomized } \\
\text { controlled studies }\end{array}$ & $\begin{array}{l}\text { Eradication } \\
\text { rate }(\%)\end{array}$ & $\begin{array}{l}\text { Eradication } \\
\text { rate }(\mathrm{n})\end{array}$ & reference & $\begin{array}{l}\text { Toxicity in on } \\
\text { label use }\end{array}$ & Daily cost \\
\hline Linezolid & Yes & 85,4 & $205 / 240$ & {$[35]$} & + & +++ \\
\hline Tigecycline & Yes & 78,1 & $25 / 32$ & [9] & + & +++ \\
\hline Daptomycin & Yes & 75 & $21 / 28$ & {$[10]$} & + & +++ \\
\hline Vancomycin & Yes & 68,8 & $152 / 221$ & [35] & ++ & ++ \\
\hline TMP-SMX & No & 53 & $26 / 49$ & {$[64]$} & + & + \\
\hline Rifampicin & No & 53 & $26 / 49$ & {$[64]$} & + & + \\
\hline Fosfomycin & No & n.a. & n.a. & n.a. & + & + \\
\hline Clindamycin & No & n.a. & n.a. & n.a. & + & + \\
\hline Quino./dalfo & No & n.a. & n.a. & n.a. & +++ & +++ \\
\hline
\end{tabular}

Toxicity: $+=$ mild to moderate,$++=$ moderate to severe,$+++=$ severe

Daily cost: $+=5-25$ Euro/day, $++=25-50$ Euro $/$ day,$+++\geq 50$ Euro $/$ day

TMP-SMX = trimethoprim-sulfamethoxazole

weight, changing renal function, and vancomycin troughs. There was no correlation found between vancomycin trough levels $(0-5,>5-10 ;>10-15,>15$ $\mu \mathrm{g} / \mathrm{ml}$ ) and clinical or microbiological outcome [35]. Moreover, with high $(>15 \mu \mathrm{g} / \mathrm{ml})$ trough levels the risk for nephrotoxicity is substantially increasing [60]. When vancomycin is combined with aminoglycosides, the creatinine rise may be as high as 35\% [61]. Finally, unfavourable clinical outcomes under vancomycin therapy have been shown to be referred to an increasing resistance with a minimum inhibitory concentration (MIC) $>1 \mu \mathrm{g} / \mathrm{ml}$ [62]. Unfortunately, many clinicians are not provided with MIC data of vancomycin when clinical decisions have to be made. Taking all these issues together, it appears to be a reasonable approach to dispense with vancomycin as a first-line treatment for severe cSSTI and to use it only if other treatment options are not tolerated or available (Table 3).

\author{
ANTIBIOTICS WITHOUT DATA FROM \\ CONTROLLED TRIALS \\ (TRIMETHOPRIM-SULFAMETHOXAZOLE, \\ RifAMPICIN, FOSFOMYCIN, CLINDAMYCIN, \\ QUINOPRISTIN/DALFOPRISTIN)
}

The good tissue penetration, the oral formulation and the low costs make trimethoprim-sulfamethoxazole (TMP-SMX) an attractive alternative to newer more expensive drugs or those which require intravenous application (glycopeptides, daptomycin, tigecycline). In vitro TMP-SMX is rapidly bactericidal against MRSA and has been shown to have a better in vitro bactericidal activity against MRSA than linezolid, rifampicin, clindamycin or minocycline [63]. Unfortunately we were unable to find prospective studies of TMP-SMX in treating patients with cSSTI caused by MRSA. The only available randomized doubleblinded trial compared TMP-SMX (1g twice daily) 
Table 3. Clinical decision-making for the choice of antibiotic with activity against MRSA according to the severity of disease.

\begin{tabular}{|c|c|c|c|c|}
\hline severity of infection & characteristics & setting & preferred route & substances \\
\hline mild & $\begin{array}{l}\text { - limited local signs } \\
\text { - no systemic signs } \\
\text { - no surgery required } \\
\text { - patient stable }\end{array}$ & outpatient & oral & $\begin{array}{l}\text { TMP-SMX } \pm \text { rifampicin } \\
\text { clindamycin* }{ }^{*} \\
\text { linezolid* }\end{array}$ \\
\hline moderate & $\begin{array}{l}\text { - marked local signs } \\
\text { - systemic signs measurable } \\
\text { - surgery required } \\
\text { - patient stable }\end{array}$ & $\begin{array}{l}\text { hospitalized, } \\
\text { general ward }\end{array}$ & $\begin{array}{l}\text { initially i.v. } \\
\text { sequential oral } \\
\text { treatment }\end{array}$ & $\begin{array}{l}\text { linezolid* } \\
\text { tigecycline\# } \\
\text { daptomycin } \\
\text { vancomycin } \\
\text { linezolid* } \\
\text { clindamycin* } \diamond \\
\text { TMP-SMX } \pm \text { rifampicin }\end{array}$ \\
\hline severe & $\begin{array}{l}\text { - massive local and/or } \\
\text { systemic signs } \\
\text { - surgery required } \\
\text { - patient unstable }\end{array}$ & $\begin{array}{l}\text { inpatient, } \\
\text { intensive } \\
\text { care }\end{array}$ & $\begin{array}{l} \\
\text { sequential oral } \\
\text { treatment }\end{array}$ & $\begin{array}{l}\text { linezolid* } \\
\text { daptomycin } \\
\text { [bacteremia] } \\
\text { tigecycline \# } \\
\text { [polymicrobial inf.] } \\
\text { (vancomycin) } \\
\text { linezolid* } \\
\text { clindamycin* } \diamond \\
\text { TMP-SMX } \pm \text { rifampicin }\end{array}$ \\
\hline
\end{tabular}

* preferred in cMRSA infections

\# not indicated in diabetic foot infections

$\diamond=$ if susceptible

TMP-SMX = trimethoprim-sulfamethoxazole

(vancomycin $)=$ to be used only if other drugs are not tolerated or not available

plus rifampicin (300 $\mathrm{mg}$ twice daily) versus novobiocin (500 $\mathrm{mg}$ twice daily) and rifampicin $300 \mathrm{mg}$ twice daily) for MRSA-decolonization [64]. The eradication rate was 53\% (TMP-SMX plus rifampicin) and $67 \%$ (novobiocin plus rifampicin), respectively. During therapy, 14\% (7/49 patients) of the TMP-SMX group developed emergence of resistance to rifampicin.

Fosfomycin has an in vitro bactericidal activity against MRSA. The pharmacokinetic properties of the drug (excellent tissue penetration) make it appear reasonable to use fosfomycin for MRSA caused cSSTI, particularly in combination with other substances [6567]. To the best of our knowledge there are only limited controlled clinical data on the use of fosfomycin in cSSTI caused by MRSA from a compassionate use study $[67,68]$. Unsolved questions of dosage, a rapid development of resistance under treatment and potential severe side effects (liver failure) are matters of concern [69].

Quinopristin/dalfopristin (Q/D) is a semisynthetic mixture of two streptogramin antibiotics. Both substances have a bacteriostatic mechansim of action against Gram-positive bacteria, but in combination bactericidal activity can be observed [70]. It is inactive against Enterococcus faecalis. We could not find any controlled data regarding the use of Q/D for MRSAcaused cSSTI. There are only retrospective data for the treatment of VRE infections [71]. The substantial side effect profile (severe myalgia, severe venous irritation, rapid emergence of resistance, interaction with cytochrome P450 system) have led to the abandonment of the Q/D [72].

Clindamycin may be an alternative in MRSA-caused cSSTI, although resistance to this agent is a problem. The penetration of the drug into soft tissues, that can be administered both i.v. and orally, is high. Clindamycin is an effective inhibitor of protein biosynthesis, making it like linezolid to a valuable drug particularly in cases of CA-MRSA [73]. Data from controlled trials do not exist to date, but efficacy has been shown in case series [74]. The toxicity profile of clindamycin is tolerable. The possible development of Clostridium difficile-associated colitis needs close clinical observation under therapy.

The lack of evidence from controlled studies with regard to efficacy and safety is a substantial flaw of all of the above mentioned compounds. Many of the randomized trials, that have been performed for approval of substances in cSSTI, were criticized not having met all of the FDA criteria for complicated SSTI [7, 56]. Nevertheless, as seen before the background of data from pivotal trials for linezolid, tigecycline, daptomycin and vancomycin $[8-10,35]$, the administration of drugs without evidence from controlled trials needs to be considered very carefully, particularly under medicolegal aspects. 


\section{COLONISATION OR INFECTION?}

The differentiation between colonisation and infection in cSSTI is of paramount clinical importance for the initiation of an antimicrobial treatment. The clinical differentiation between colonisation and infection can be extremely difficult even for experienced physicians. On one hand the recognition of an infection can be complicated in a case of a diabetic foot syndrome when classical local and systemic signs of infection are disguised by an ischemic component of the disease. On the other hand a substantial immunosuppression (e.g. leucopenia during chemotherapy) might be a reason for the initiation of an antibiotic treatment even in case of colonisation. In a Cochrane review the results of a treatment of MRSA colonization with topical or systemic administration of several agents in immunocompetent patients has been investigated. Six randomized studies with 384 patients were included. The authors did not find superiority for any drug over placebo except for the nasal decolonisation with mupirocin [75]. Development of resistance and toxicity were significantly more frequent in the verum group. Therefore, antibiotic treatment of colonisation of skin and soft tissues with MRSA is only indicated in rare cases.

\section{Is There a Clinically Relevant DIFFERENCE BETWEEN BACTERIOSTATIC AND BACTERICIDAL DRUGS?}

The general characteristics of anti-MRSA substances are listed in Table 1. In Table 2 the controlled clinical data of the compounds are listed. From the analyzed drugs, vancomycin, daptomycin, TMP-SMP, Q/D, fosfomycin and rifampicin are described as bactericidal, whereas linezolid, clindamycin and tigecycline as bacteriostatic. Bacteriostatic and bactericidal categorizations in clinical practice are not absolute and can lead to false assumptions concerning antimicrobial therapy, especially if major pharmacokinetic and pharmacodynamic parameters like tissue penetration and plasma protein binding are ignored. The bacteriostatic agent linezolid has shown non-significant superiority over the bactericidal vancomycin in every controlled study for the treatment of cSSTI caused by MRSA $[8,31$, 35], whereas the rapidly bactericidal drug daptomycin has failed to reach superiority over comparator substances in cSSTI [10]. It is important to distinguish microbiological and clinical definitions. To date, there has not been found any significant advantage for bactericidal agents in the treatment of cSSTI. The ultimate guide to treatment of any infection must be clinical outcome [76].

\section{TREATMENT RECOMMENDATIONS FOR ANTIMICROBIAL THERAPY}

The adequate empirical antibiotic treatment in cSSTI caused by MRSA has been shown to be a significant predictor for treatment success [77]. The antibiotic treatment of cSSTI is well reviewed in the published guidelines [78-81]. Any clinical guideline for antimicrobial treatment of (MRSA-caused) cSSTI should follow the clinical presentation of the affected patient. Differentiation between outpatient treatment (preferably with oral agents), and hospitalised patients with or without sepsis (primarily intravenously, followed by oral treatment if possible) is set out in Table 3. Although concerns remain about the quality of randomized trials in cSSTI [56], linezolid, tigecycline, daptomycin and vancomycin have proven efficacy and safety in MRSA-caused cSSTI [8-10, 35]. None of these drugs showed significant superiority regarding clinical cure and eradication rates. To date, linezolid offers by far the greatest number of patients included in trials with cSSTI caused by MRSA and showed a strong tendency of superiority over vancomycin in terms of clinical success rates and eradication rates $[34,35]$. Due to its pharmacokinetic unreliability, its toxicity and increasing resistance ("MIC-creep") and relatively poor results in the treatment of severely ill patients, the administration of vancomycin should be restricted only to cases of moderate severity of infection or if other treatment options are not tolerated or available [57].

In cSSTI caused by MRSA it is useful to differentiate between monomicrobial and polymicrobial infections [80]. In those cases, agents merely active against Gram-positive bacteria (linezolid, daptomycin, vancomycin) have to be combined with drugs showing activity against Gram-negative and anaerobic organisms. Tigecycline is an alternative in polymicrobial infections excluding diabetic foot infections [9]. Daptomycin appears to be a treatment option for cases of cSSTI and MRSA bacteremia [10, 80].

cSSTI caused by VRE have not been investigated under conditions of controlled trials. Treatment recommendations (linezolid, tigecycline) are based on in vitro data $[8,9]$ as well as personal experience and are summarized in Table 4 modified according to [81].

In cSSTI caused by resistant Gram-negative bacteria (primarily ESBL-producing or carbapenem-resistant strains), carbapenems (ESBL) and tigecycline (ESBL and carbapenem-resistant bacteria) are the only available in vitro effective drugs with a tolerable toxicity (Table 4). However, evidence from controlled trials is almost completely missing [50, 51]. Colistin has been shown to be associated with poorer survival compared to controls, a significantly higher rate of renal toxicity and a high rate of subsequent infections caused by Proteus spp. [82].

As long as more than one therapeutic alternative is available, the application of antibiotic diversity appears to be a very useful tool in order to reduce the antibiotic selective pressure on any substance as a part of an antibiotic stewardship program $[15,17]$.

Despite national and international recommendations and guidelines, it is important to stress that local epidemiology and antibiotic resistance patterns are important in determining empirical antibacterial therapy.

Treatment duration can usually be confined to 7 days, providing that the patient and wound have improved clinically and blood inflammatory signs (CRP, leucocytes) have substantially reduced. However, controlled clinical data regarding the duration of treatment in cSSTI are not available to date. 
Table 4. Antibiotics against VRE, ESBL and carbapenem-resistant bacteria in cSSTI.

\begin{tabular}{lll}
\hline Organism & Antibiotic & Duration \\
\hline VRE & $\begin{array}{l}\text { Linezolid } \\
\text { Tigecycline }\end{array}$ & 7 days \\
& $\begin{array}{l}\text { Carbapenem group 1 and 2 } \\
\text { ESBL }\end{array}$ & 7 days \\
& $\begin{array}{l}\text { Fosfomycin } \\
\text { Colistin }\end{array}$ & \\
& Tigecycline \\
Carbapenem & Colistin & 7 days \\
resistant bac. & & \\
\hline
\end{tabular}

$+=$ combination therapy necessary

\section{SUMMARY}

- The treatment of cSSTI caused by resistant bacteria relies on a combination of surgical and antimicrobial treatment. Good quality controlled clinical data for the efficacy and safety is only available for MRSA-caused cSSTI.

- Linezolid, tigecycline, daptomycin and vancomycin have shown efficacy and safety in MRSA-caused cSSTI. None of these drugs showed significant superiority regarding clinical cure and eradication rates. Linezolid offers to date by far the greatest number of patients included in controlled trials with a strong tendency of superiority over vancomycin.

- Tigecycline is an alternative in polymicrobial infections excluding diabetic foot infections.

- Daptomycin is an effective treatment option for cases of cSSTI and MRSA bacteremia.

- Due to its pharmacokinetic shortfalls, the toxicity and the increasing resistance and poor clinical results in the treatment of severe infections, the administration of vancomycin should be restricted only to cases of mild or moderate severity of infection or if other treatment options are not tolerated or available.

- cSSTI caused by resistant Gram-negative bacteria (mainly ESBL-producing or carbapenem-resistant strains) are a matter of great concern. Carbapenems (ESBL) and tigecycline (ESBL and carbapenem-resistant bacteria) are the only available effective drugs with a tolerable toxicity.

- The development of new antibiotics in this area is urgently required in order to avoid a postantibiotic era without any antimicrobial treatment option.

- An individual approach for every patient is essential to establish an optimal treatment regimen. As long as more than one therapeutic alternative is available, the application of antibiotic diversity is a useful tool in order to reduce the antibiotic selective pressure on particular agent.

Acknowledgements: This article is dedicated to my dear friend Kamal.
Transparency declarations: CE has received speaker honoraria from Pfizer, Wyeth, Bayer, MSD and Novartis and has participated on advisory boards for Wyeth and Pfizer. MD has received speaker honoraria and served on advisory boards for Pfizer, Wyeth, Bayer, Janssen- Cilag, Novartis.

\section{REFERENCES}

1. DiNubile MJ, Lipsky BA. Complicated infections of skin and skin structures: when the infections is more than skin deep. J Antimicrob Chemother 2004; 53 (Suppl 2):37-50

2. Nichols RL, Florman S. Clinical presentation of soft tissue infections and surgical site infections. Clin Inf Dis 2001; 33; S83-93

3. Lipsky BA. Cellulitis, erysipelas and necrotizing soft tissue infections. Best Practice of Medicine. http://www.bestpracticeofmedicine.com 2002

4. Engel C., Brunkhorst FM, Bone HG et al. Epidemiology of sepsis in Germany: results from a national prospective multicenter study. Intensive Care Med 2007; 33:606-18

5. Kingston D, Seal DV. Current hypotheses for synergistic microbial gangrene. Br J Surg 1990; 77: 260

6. Eckmann C. Severe skin and soft tissue infections. Intensivmed 2009;46: 480-485

7. Center for Drud Evaluation and Research (CDER). Uncomplicated and complicated skin and skin-structure infections - developing antimicribial drugs for treatment.

http:/ /www.fda.gov/cder/guidance/2566dft.pdf 1998

8. Weigelt J, Itani $\mathrm{K}$ et al. Linezolid versus vancomycin in the treatment of complicated skin and soft tissue infections. Antimicrob Agents Chemother 2005; 49: 22602266

9. Ellis-Grosse EJ, Babinchak T et al. The efficacy and safety of tigecycline in the treatment of skin and skinstructure infections: results of 2 double-blind phase 3 comparison studies with vancomycin-aztreonam. Clin Infect Dis 2005; 41: S341-353

10. Arbeit RD, Maki D et al. The safety and efficacy of daptomycin fort he treatment of complicated skin and skin-structure infections. Clin Inf Dis 2004; 38: 16731681

11. Wilson SE, O’Riordan W, et al. Telavancin versus vancomycin fort he treatment of complicated skin and skin-structure infections associated with surgical procedures. Am J Surg 2009; 197: 791-796

12. Jones ME et al. Epidemiology and antibiotic susceptibility of bacteria causing skin and soft tissue infections in the USA and Europe: a guide to appropriate antimicrobial therapy. Int J Antimicrob Agents 2003: 406-419

13. Giordano P et al. Sequential intravenous/oral moxifloxacin versus intravenous piperacillin-tazobactam followed by oral amoxicillin-clavulanate for the treatment of complicated skin and skin structure infection. Int J Antimicrob Agents 2005; 26(5):357-65

14. Moet GJ et al. Contemporary causes of skin and soft tissue infections in North America, Latin America, and Europe: report from the SENTRY Antimicrobial Surveillance Program (1998-2004). Diagn Microbiol Infect Dis 2007; 57(1): 7-13

15. Dryden M. Complicated skin and soft tissue infection. J Antimicrob Chemother. 2010;65 (S3):iii35-44

16. Wilcox MH. The tide of antimicrobial resistance and selection. Int J Antimicrob Agents 2009; 34 S3: S610. 
17. Nathwani D. New antibiotics for the management of complicated skin and soft tissue infections: are they any better? Int J Antimicrob Agents 2009; 34: S24-9.

18. Wilcox MH. Tigecycline and the need for a new broadspectrum antibiotic class. Surg Infect (Larchmt) 2006; 7: 69-80.

19. Hawkey PM, Jones AM. The changing epidemiology of resistance. J Antimicrob Chemother 2009; 64: i3-10.

20. Boucher HW, Talbot GH, Bradley JS et al. Bad bugs, no drugs: no ESKAPE! An update from the Infectious Diseases Society of America. Clin Infect Dis 2009; 48: $1-12$

21. Talbot GH, Bradley J, Edwards JE, Jr. et al. Bad bugs need drugs: an update on the development pipeline from the Antimicrobial Availability Task Force of the Infectious Diseases Society of America. Clin Infect Dis 2006; 42: 657-68.

22. Rice LB. Federal funding for the study of antimicrobial resistance in nosocomial pathogens: no ESKAPE. J Infect Dis 2008; 197: 1079-81.

23. Dryden MS. Skin and soft tissue infection: microbiology and epidemiology. Int J Antimicrob Agents 2009; 34 Suppl 1: S2-7.

24. Chaberny IF, Ziesing S, Mattner F, Barwolff S et al. The burden of MRSA in four German university hospitals. Int J Hyg Environ Health 2005;208:447-453

25. Engemann JJ, Carmeli Y, Cosgrove SE, Fowler VG et al. Adverse clinical and economic outcomes attributable to methicillin resistance among patients with Staphylococcus aureus surgical site infection. Clin Infect Dis 2003;36:592-598

26. Moran GJ, Krishnadasan A, Gorwitz RJ, Fosheim GE et al. Methicillin-resistant Staphylococcus aureus among patients in the emergency department. N Eng J Med 2006;355:666-674

27. Young LM, Price CS. Community-acquired methicillinresistant Staphylococcus aureus emerging as important cause of necrotizing fasciitis. Surg Infect 2008;9:469474

28. Dodds TJ, Hawke CI. Linezolid versus vancomycin for MRSA skin and soft tissue infections. ANZ J Surg 2009;79:629-635

29. Moellering RC. Linezolid: the first oxazolidinone antimicrobial. Ann Intern Med 2003;138:135-142

30. Stevens DL, Smith LG, Bruss JB et al. and the Linezolid Skin and Soft Tissue Infections Study Group. Randomized comparison of linezolid (PNU-100766) versus oxacillin-dicloxacillin for the treatment of complicated skin and soft tissue infections. Antimicrob Agents Chemother 2000;44:3408-3413

31. Stevens DL, Herr D, Lampris $H$ et al. Linezolid versus vancomycin for the treatment of methicillin-resistant Staphylococcus aureus infections. Clin Infect Dis 2002;34:1481-1490

32. Lipsky BA, Itani K, Norden C: and the Linezolid Diabetic Foot Infections Study Group. Treating foot infections in diabetic patients: a randomized, multicenter, open-label trial of linezolid versus ampicillin-sulbactam/amoxicillin-clavulanate. Clin Infect Dis 2004;38: $17-24$

33. Weigelt J, Itani K, Stevens DL et al. Linezolid eradicates MRSA better than vancomycin from surgical-site infections. Am J Surg 2004;188:760-766

34. Sharpe JN, Shively EH, Polk HC Jr. Clinical and economic outcomes of oral linezolid versus IV vancomycin in the treatment of MRSA-complicated, lower-extremity skin and soft-tissue infections caused by methicillin-resistant Staphylococcus aureus. Am J Surg 2005;189:425-428
35. Itani KMF, Dryden MS, Bhattacharyya H, Kunkel MJ et al. Efficacy and safety of linezolid versus vancomycin for the treatment of complicated skin and soft-tissue infections proven to be caused by methicillin-resistant Staphylococcus aureus. Am J Surg 2010 ;

36. Gerson SL; Kaplan SL, Bruss JB et al. Hematological effects of linezolid: summary of clinical evidence. Antimicrob Agents Chemother 2002;46:2723-2726

37. Narita M, Tsuji BT, Yu VL. Linezolid-associated peripheral and optic neuropathy, lactic acidosi, and serotonine syndrome. Pharmacotherapy 2007;27:118997

38. Steenbergen JN, Alder J, Thorne GM, Tally FC. Daptomycin: a lipopeptide antibiotic for the treatment of serious gram-positive infections. J Antimicrob Chemother 2005;55:283-288

39. Lipsky BA, Stoutenburgh U. Daptomycin for treating infected diabetic foot ulcers: evidence from a randomized, controlled trial comparing daptomycin with vancomycin or semi-synthetic penicillins for complicated skin and soft tissue infections. J Antimicrob Chemother 2005;55:240-245

40. Lamp K et al. Daptomycin for the treatment of Staphylococcus aureus bacteremia. Clin Res Cardiol 2007;96: 447-448

41. Fowler VG, Boucher HW, Corey GR et al. Daptomycin versus standard therapy for bacteremia and endocarditis caused by Staphylococcus aureus. N Eng J Med 2006;355: 653-665

42. Nicolau DP. Management of complicated infections in the era of antimicrobial resistance: the role of tigecycline. Expert Opin Pharmacother 2009; 10: 121322.

43. Kresken M, Leitner E, Brauers J et al. Susceptibility of common aerobic pathogens to tigecycline: results of a surveillance study in Germany. Eur J Clin Microbiol Infect Dis 2009; 28: 83-90.

44. Kresken M, Leitner E, Seifert H et al. Susceptibility of clinical isolates of frequently encountered bacterial species to tigecycline one year after the introduction of this new class of antibiotics: results of the second multicentre surveillance trial in Germany (G-TEST II, 2007). Eur J Clin Microbiol Infect Dis 2009; 28: 100711.

45. Swoboda S, Ober M, Hainer C et al. Tigecycline for the treatment of patients with severe sepsis or septic shock: a drug use evaluation in a surgical intensive care unit. J Antimicrob Chemother 2008; 61: 729-33.

46. Chemaly RF, Hanmod SS, Jiang Y et al. Tigecycline use in cancer patients with serious infections: a report on 110 cases from a single institution. Medicine (Baltimore) 2009; 88: 211-20.

47. Vasilev K, Reshedko G, Orasan R et al. A Phase 3, open-label, non-comparative study of tigecycline in the treatment of patients with selected serious infections due to resistant Gram-negative organisms including Enterobacter species, Acinetobacter baumannii and Klebsiella pneumoniae. J Antimicrob Chemother 2008; 62 Suppl 1: i29-40.

48. Poulakou G, Kontopidou FV, Paramythiotou E et al. Tigecycline in the treatment of infections from multidrug resistant gram-negative pathogens. J Infect 2009; 58: 273-84.

49. Gordon NC, Wareham DW. A review of clinical and microbiological outcomes following treatment of infections involving multidrug-resistant Acinetobacter baumannii with tigecycline. J Antimicrob Chemother 2009; 63: $775-80$ 
50. Bassetti M, Nicolini L, Repetto E, Rghi E, Del Bono V, Viscoli C. Tigecycline use in derious mosocomial infections: a drug use evaluation. BMC Infect Dis 2010; 10:287

51. Eckmann C, Heizmann WR, von Eiff C, Leitner E, Löschmann PA, Bodmann KF. Prospective, non-interventional multicentre trial of tigecycline in the treatment of severely ill patients. Chemother J 2010;19:165166

52. Petersen PJ, Ruzin A, Tuckman M, Jones $\mathrm{CH}$, In vitro activity of tigecycline against patient isolates collected during phase 3 clinical trials for diabetic foot infections. Diagn Microbiol Infect Dis 2010;66:407$418 \mathrm{~h}$

53. Hung WY, Kogelman L, Volpe G et al. Tigecycline-induced acute pancreatitis: case report and literature review. Int J Antimicrob Agents 2009; 34: 486-9.

54. http://www.fda.gov/Drugs/DrugSafety/ucm224370.htm

55. Daschner FD, Frank U, Kuemmel S, Schmidt-Eisenlohr E et al. Pharmacokinetics of vancomycin in serum and tissue of patients undergoing open-heart surgery. J Antimicrob Chemother 1987;19:802-4

56. McClaine RJ, Husted TL, Hebbeler-Clark S, Solomkin JS. Meta-anaysis of trials evaluating parenteral antimcrobial therapy for skin and soft tissue infections. Clin Infect Dis 2010;50:1120-1126

57. Gonzalez C, Rubio M, Romero-Vivas J et al. Bacteremic pneumonia due to Staphylococcus aureus: A comparicon of disease caused by methicillin-resistant and methicillin-susceptible organisms. Clin Infect Dis 1999;29:1171-1177

58. Deresinski S. Vancomycin in combination with other antibiotics for the treatment of serious methicillin-resistant Staphylococcus aureus infections. Clin Infect Dis 2009; 49:1072-1090

59. Rybak M, Lomaestro B, Rotschafer JC, Moellering R et al. Therapeutic monitoring of vancomycin in adult patients: A consensus review of the American Society of Health-System Pharmacists, the Infectious Diseases Society of America, and the Society of Infectious Diseases Pharmacists. Am J Health-Syst Pharm 2009; 66:82-98

60. Hermsen ED, Hanson M, Sankaranarayanan J, Stoner JA et al. Clinical outcomes and nephrotoxicity associated with vancomycin trough concentrations during treatment of deep-seated infections. Expert Opin Drug Saf 2010;9:9-14

61. Farber BF. Retrospective study of the toxicity of preparations of vancomycin from 1974 to 1981. Antimicrob Agents Chemother 1983;23:138-141

62. Sakoulas G, Moise-Broder PA, Schentag J, Forrest A et al. Relationship of MIC and bactericidal activity to efficacy of vancomycin for treatment of methicillin-resistant Staphylococcus aureus bacteremia. J Clin Microbiol 2004;42:2398-2402

63. Kaka AS, Rueda AM, Shelburne SA, Hulten K, Hamill RJ, Musher DM. Bactericidal activity of orally available agents against methicillin-resistant Staphylococcus aureus. J Antimicrob Chemother 2006;58:680-683

64. Walsh TJ, Standiford HC, Reboli AC, John JF et al. Randomized double-blinded trial of rifampicin with either novobiocin or trimethoprim-sulfamethoxazole against methicillin-resistant Staphylococcus aureus colonization: prevention of antimicrobial resistance and effect of host factors on outcome. Antimicrob Agents Chemother 1993;37:1334-1342

65. Stengel, D; Gorzer, E; Schintler, M; Legat, FJ; Amann, W; Pieber, T; Ekkernkamp, A; Graninger, W. Secondline treatment of limb-threatening diabetic foot infec- tions with intravenous fosfomycin. J Chemother 2005; 17(5): 527-35.

66. Falagas, ME; Giannopoulou, KP; Kokolakis, GN; Rafailidis, PI. Fosfomycin: use beyond urinary tract and gastrointestinal infections. Clin Infect Dis 2008 ; 46(7) : 1069-77.

67. Falagas, ME; Roussos, N; Gkegkes, ID; Rafailidis, PI; Karageorgopoulos, DE. Fosfomycin for the treatment of infections caused by Gram-positive cocci with advanced antimicrobial drug resistance: a review of microbiological, animal and clinical studies. Expert Opin Investig Drugs 2009; 18(7): 921-44.

68. Legat, FJ; Maier, A; Dittrich, P; Zenahlik, P; et al. Penetration of Fosfomycin into Inflammatory Lesions in Patients with Cellulitis or Diabetic Foot Syndrome. Antimicrob Agents Chemother 2003; 47(1): 371374.

69. Durupt S, Josserand RN, Sibille M, Durieu I. Acute, recurrent fosfomycin-induced liver toxicity in an adult patient with cyctic fibrosis. Scand J Infect Dis 2001;33: 391-2

70. Eliopoulos GM. Quinopristin-dalfopristin and linezolid: evidence and opinion. Clin Infect Dis 2003;36:473481

71. Raad I, Hachem R, Hanna H, Afif C et al. Prospective, randomized study comparing quinopristin-dalfopristin with linezolid in the treatment of vancomycin-resistant Enterococcus faecium infections. J Antimicrob Chemother 2004;53:646-649

72. Paterson DL. Clinical experience with recently approved antibiotics. Curr Opin Pharmacol 2006;6:485490

73. Barnes EV, Dooley DP, Hepburn MJ, Baum SE. Outcomes of community-acquired, methicillin-resistant Staphylococcus aureus, soft tissue infections treated with antibiotics other than vancomycin. Mil Med 2006; 171:504-507

74. Hyun DY, Mason EO, Forbes A, Kaplan SL. Trimethoprim-sulfamethoxazole or clindamycin for treatment of community-acquired methicillin-resistant Staphylocuccus aureus skin and soft tissue infections. Pediatr Infect Dis J. 2009;28:57-59

75. Loeb M, Main C, Walker-Dilks C, Eady A. Cochrane Database Syst Rev 2003;(4):CD003340

76. Pankey GA, Sabath LD Clinical relevance of bacteriostatic versus bactericidal mechanisms of action in the treatment of grampositive bacterial infections. Clin Infect Dis 2004;38:864-870

77. Szumowski JD, Cohen DE, Kanaya F, Mayer KH. Treatment and outcomes of infections by methicillinresistant Staphylococcus aureus at an ambulatory clinic. Antimicrob Agents Chemother 2007;51:423-428

78. Stevens DL, Bisno AL et al. Practice guidelines for the diagnosis and management of skin and soft tissue infections. Clin Inf Dis 2005; 41: 1373-1406

79. Eron LJ, Lipsky BA Low DE et al. Managing skin and soft tissue infections: expert panel recommendations on key decision points. J Antimicrob Chemother 2003;52 (S1:i3-17

80. Gould FK, Brindle R, Chadwick PR et al. Guidelines for the prophylaxis and treatment of methicillin-resistant Staphylococcus aureus (MRSA) infections in the United Kingdom. J Antimicrob Chemother 2009;63: 849-861

81. Eckmann C. Isenmann R, Kujath P et al. Intraabdominal infections. In: Bodmann KF, Grabein B et al. Recommendations for calculated parenteral initial therapy of bacterial diseases in adults - update 2010. ISBN 9783-00-031623-4:p46-52 
82. Paul M, Bishara J, Levcovich A et al. Effectiveness and safety of colistin: prospective comparative cohort study. J Antimicrob Chemother 2010;65:1019-1027

Receuved: November 2, 2010 / Accepted: November 10, 2010

Address for correspondence:

Priv.-Doz. Dr. med. Christian Eckmann

Klinikum Peine gGmbH

Academic Hospital of Medical University Hannover

Virchowstrasse $8 \mathrm{~h}$

31226 Peine

Germany

Phone: $+49 /(0) 5171 / 931530$

Fax: $+49 /(0) 5171 / 931549$

E-mail: christian.eckmann@klinikum-peine.de

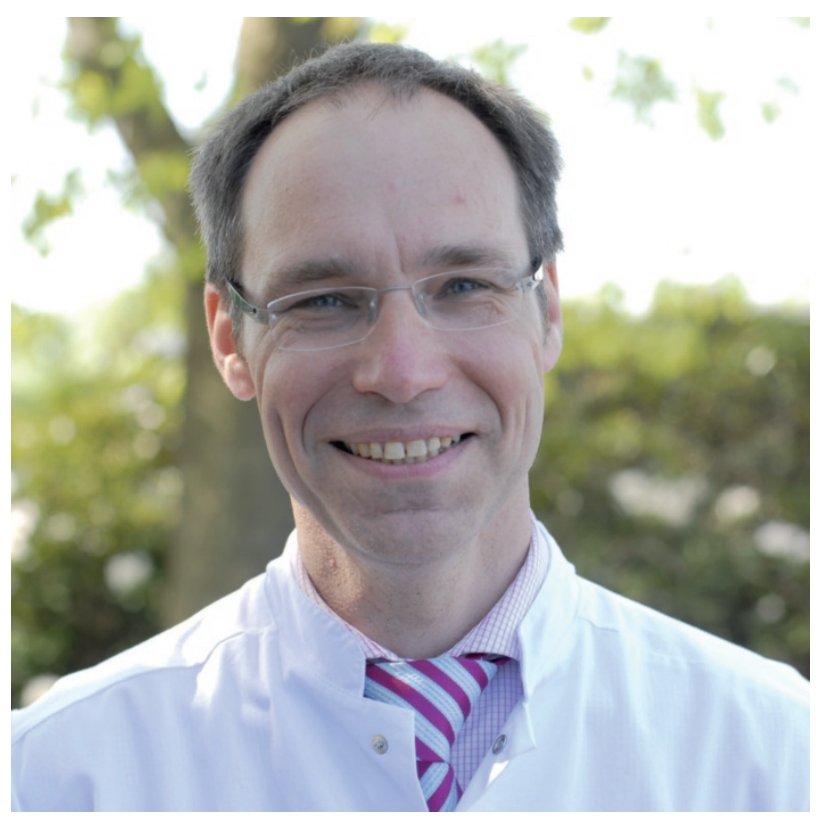

Christian Eckmann 